\title{
A Study of the Quench Sensitivity of 6061-T6 and 6069-T6 Aluminum Alloys
}

\author{
M. E. Kassner, ${ }^{1}$ P. Geantil,, ${ }^{2}$ and X. Li $^{2}$ \\ ${ }^{1}$ Department of Aerospace and Mechanical Engineering, University of Southern California, Los Angeles, CA 90089, USA \\ ${ }^{2}$ LSI Logic, Gresham, OR 97006, USA \\ Correspondence should be addressed to M. E. Kassner, kassner@usc.edu
}

Received 28 August 2010; Accepted 23 March 2011

Academic Editor: Chong Soo Lee

Copyright (c) 2011 M. E. Kassner et al. This is an open access article distributed under the Creative Commons Attribution License, which permits unrestricted use, distribution, and reproduction in any medium, provided the original work is properly cited.

The purpose of this study is to investigate the quench sensitivity of the mechanical properties of 6061 and 6069 aluminum alloys. The relationship between mechanical properties and quench delay time at various temperatures between $200-500^{\circ} \mathrm{C}$ was determined. It was concluded that the 6069-T6 was somewhat more quench sensitive than 6061, which may be consistent with the composition difference. This study also provides increased data on the quench sensitivity of the traditional alloy, 6061-T6.

\section{Introduction}

The mechanical properties of the relatively new $6 \mathrm{xxx}$ series alloy, 6069, were extensively discussed by the authors in [1$3]$. The objective of this study was to determine the quench sensitivity of the new alloy 6069, especially as compared to the traditional 6061 alloy. That is, on rapidly cooling from the solution annealing temperature by quenching, any reduction in the cooling rate translates to longer times at intermediate temperatures where "uncontrolled" nucleation can occur and lead to lower T6 properties subsequent to aging. The mechanical properties response varies for a given, decreased, cooling rate depending on the alloy composition. Gullotti et al. [4] and others $[5,6]$ found that for the 6xxx alloys, those that had higher $\mathrm{Mg}, \mathrm{Si}, \mathrm{Mn}, \mathrm{Cr}$, and $\mathrm{Zr}$ were more likely to have relatively accelerated $\mathrm{Mg}_{2} \mathrm{Si}$ precipitation leading to diminished T6 mechanical properties. Mondolfo [7] reported that $\mathrm{Cu}$ increases quench sensitivity, but Zoller et al. [5] found that $\mathrm{Cu}$ actually alleviates quench sensitivity somewhat. The alloy 6069 has been demonstrated to have superior T6 fatigue, tensile, and fracture toughness properties over $6061[1,2]$. However, the improved properties are provided in association with alloy additions $\mathrm{Mg}, \mathrm{Si}, \mathrm{Cr}$ (and $\mathrm{Cu}$ for which the effect is uncertain) which may render 6069 more quench sensitive. Thus, this investigation assessed the quench sensitivity of 6061 and 6069 , both prepared identically from extruded air slip direct chill casting (AirSlipor'ASDC). Both were solution treated at the same temperature and "quenched" into salt baths at various temperatures for various times followed by a water quench. The times at temperatures for a fixed deterioration (e.g., 5\%) of T6 tensile (yield stress and ultimate tensile stress) were determined.

\section{Experimental Methods}

The 6061 and 6069 aluminum alloys used in this study were extruded at Anodizing Inc. (Portland, Ore) from Air-Slip Direct Chill Cast (ASDC) ingots provided by Northwest Aluminum Company. 6061 ingot was extruded into solid flat bar with a thickness of $9.53 \mathrm{~mm}$ and width of $38.1 \mathrm{~mm}$. 6069 (228.6 $\mathrm{mm}$ diameter) ingot was extruded into solid round bar of $38.1 \mathrm{~mm}$ in diameter. The 6061 and 6069 ingots were pre heat treated before extrusion. The compositions of 6061 and 6069 aluminum alloys used in this study as well as 6061 sheet of an earlier (comparison) study from [4] are listed in Table 1.

The tensile specimens of 6061 and 6069 aluminum alloys of this study were cut along the extrusion direction and machined into round specimens with $2.54 \mathrm{~mm}$ diameter and $10.2 \mathrm{~mm}$ gage length. The specimens were solution heattreated at $566^{\circ} \mathrm{C}$ for 1.5 hours with an accuracy of $1.5^{\circ} \mathrm{C}$. 


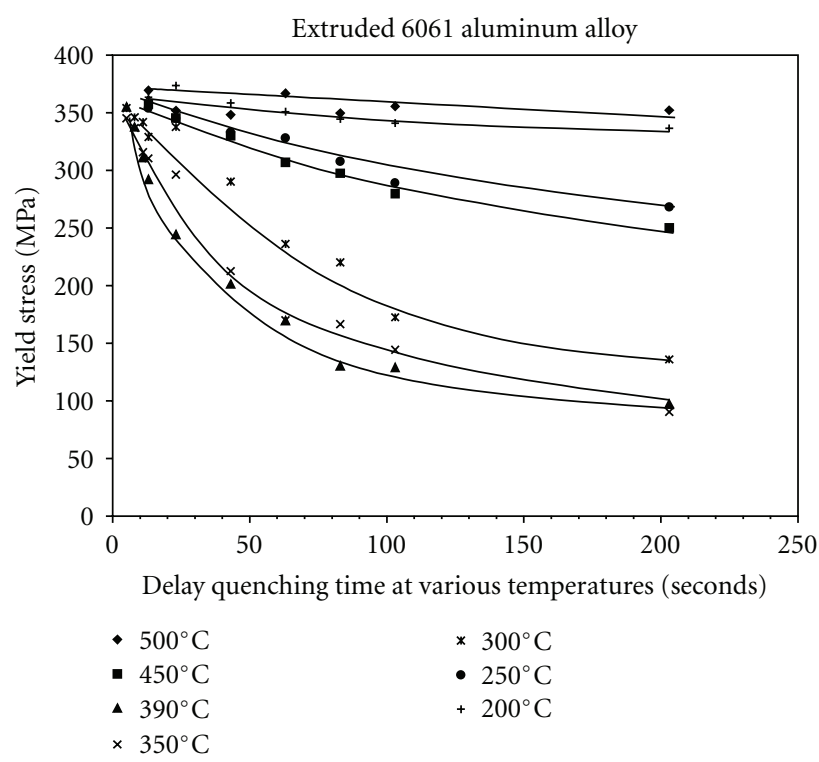

(a)

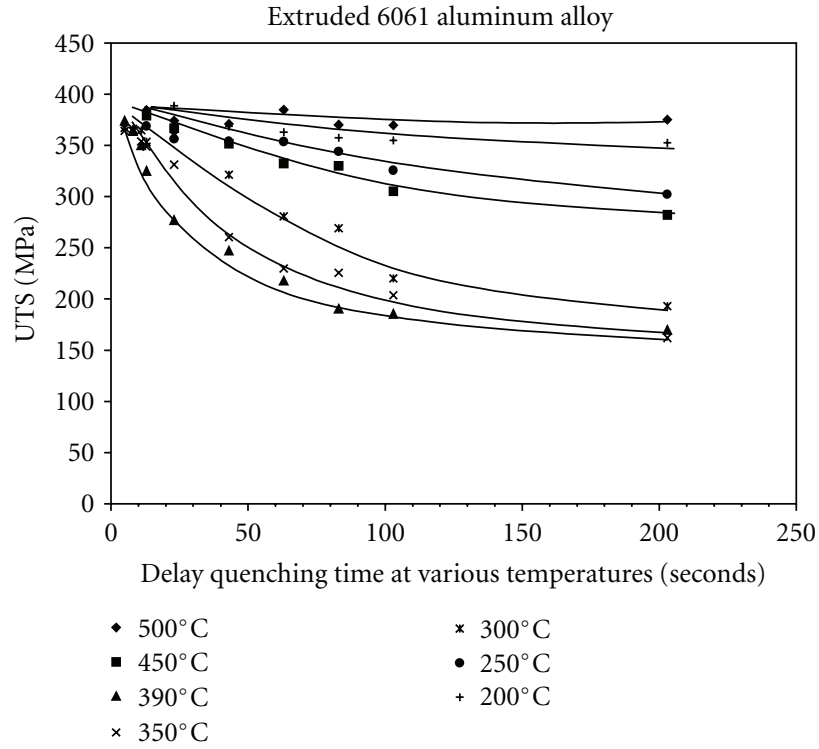

(b)

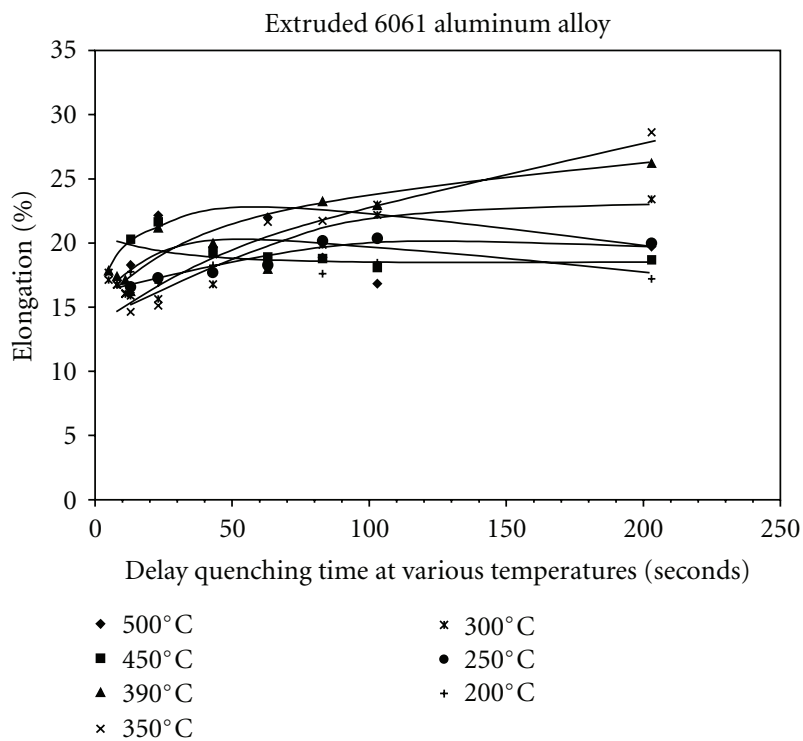

(c)

FIGURE 1: The effect of delayed quenching on the 6061-T6 (a) yield strength, (b) UTS, and (c) elongation.

TABLE 1: The composition of extruded 6061 and 6069 alloys used in this study as well as 6061 sheet [4].

\begin{tabular}{lcccccccccc}
\hline & & \multicolumn{1}{c}{ Composition, \%wt. } & \multicolumn{1}{c}{ Ti } & $\mathrm{V}$ & $\mathrm{Ga}$ & $\mathrm{Zn}$ \\
\hline 6061 (this study) & $\mathrm{Si}$ & $\mathrm{Fe}$ & $\mathrm{Cu}$ & $\mathrm{Mn}$ & $\mathrm{Mg}$ & $\mathrm{Cr}$ & 0.01 & - \\
6069 (this study) & 0.88 & 0.23 & 0.23 & 0.02 & 0.89 & 0.06 & 0.024 & 0.01 & 0.01 & 0.02 \\
6061 (from [4]) & 0.66 & 0.30 & 0.71 & - & 1.4 & 0.22 & 0.032 & 0.01 \\
\hline
\end{tabular}

The specimens were then quenched into a molten salt bath at various temperatures $\left(200-500^{\circ} \mathrm{C}\right)$ for various times $(3-200$ seconds) and then water quenched to ambient tem-perature. The (molar) composition of molten salt used in the temperature range of 300 to $500^{\circ} \mathrm{C}$ was $18.3 \% \mathrm{KCl}, 50.4 \% \mathrm{LiCl}, 8 \%$
$\mathrm{NaCl}$, and $23.3 \% \mathrm{RbCl}$. The (molar) composition of molten salt used in the temperature range of 200 to $300^{\circ} \mathrm{C}$ was $56 \%$ $\mathrm{AlCl}_{3}, 7 \% \mathrm{KCl}$, and $37 \% \mathrm{LiCl}$. Thermocouples were placed inside the center of a "control" specimen, and the time was recorded when the temperature of thermocouples was within 


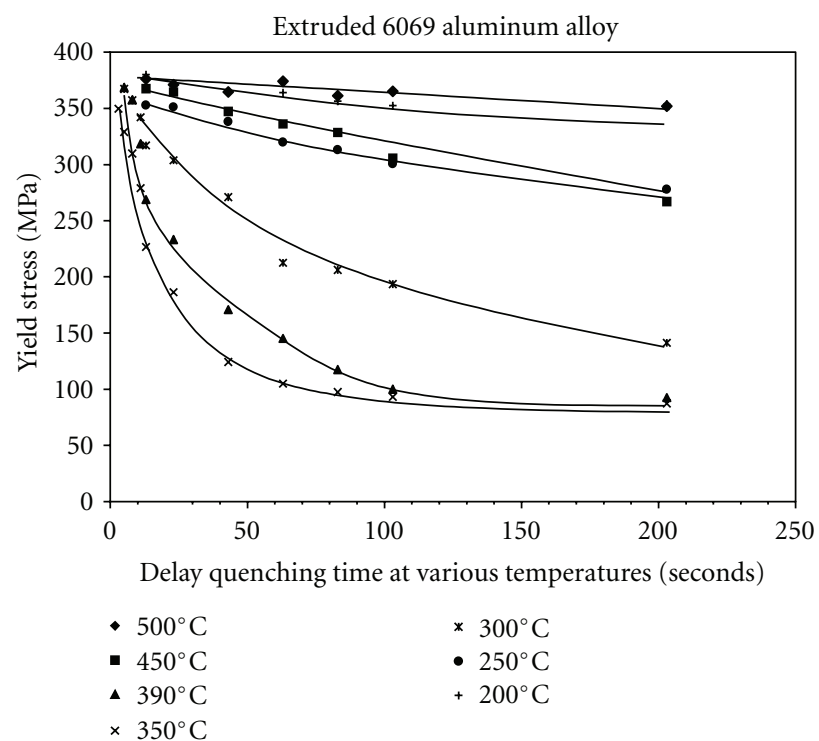

(a)

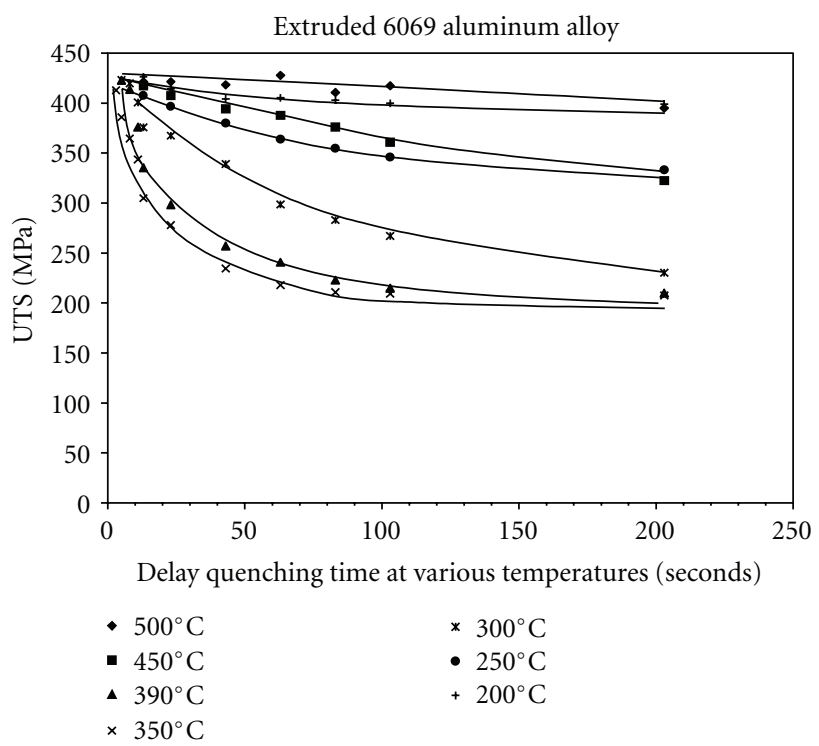

(b)

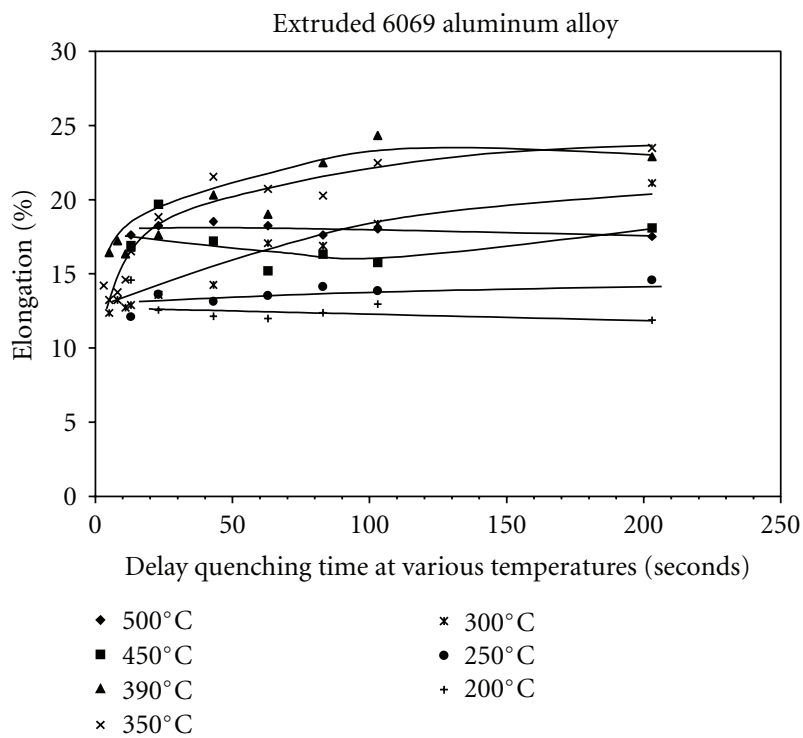

(c)

Figure 2: The effect of delayed quenching on the 6069-T6 (a) yield strength, (b) UTS, and (c) elongation.

$3^{\circ} \mathrm{C}$ of molten salt. The precipitation (T-6) treatment for extruded 6061 and 6069 specimens was $185^{\circ} \mathrm{C}$ for 8 hours.

\section{Results and Discussion}

Figures 1 and 2 show the relationship between mechanical properties (yield stress, UTS, and elongation) of the extruded 6061-T6 and 6069-T6 alloys and the delay quenching time at various (isothermal) temperatures $\left(200-500^{\circ} \mathrm{C}\right)$. It was found that the $(0.2 \%$ offset $)$ yield stress and UTS of both alloys decreased as the hold time increased at a given isothermal temperature. It was also observed that, at a given hold time, the strength of both alloys decreased as isothermal temperature decreased (from 500 to $350^{\circ} \mathrm{C}$ ) and then increased again (from 200 to $300^{\circ} \mathrm{C}$ ). The largest decreases in strength (yield and UTS) are observed at isothermal temperatures of $350-390^{\circ} \mathrm{C}$ for extruded 6061 and 6069 . It was also observed that elongation (\%) slightly increased as the hold time increased, especially at isothermal temperatures of $300-390^{\circ} \mathrm{C}$.

Based on these results, the time-temperature curves at 95\% of maximum (small decrease in mechanical behavior) yield stress and UTS for extruded 6061-T6 and 6069-T6 aluminum alloys are illustrated in Figure 3. The data of $95 \%$ of maximum strength were sometimes interpolated from the strength data. It is observed that extruded 6061 allows more time for a decrease to $95 \%$ of maximum strength than extruded 6069 at a given isothermal temperature. This 


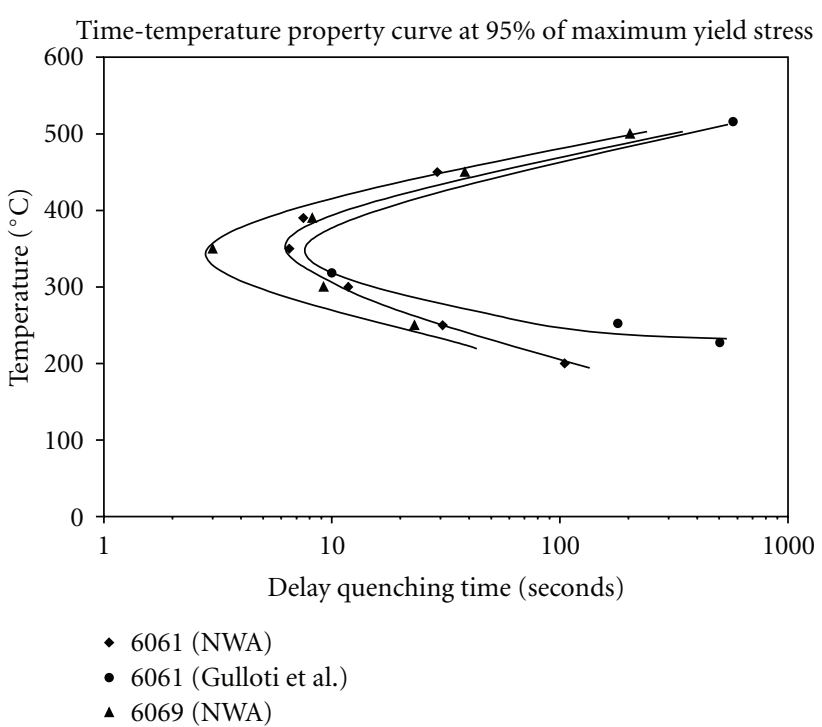

(a)

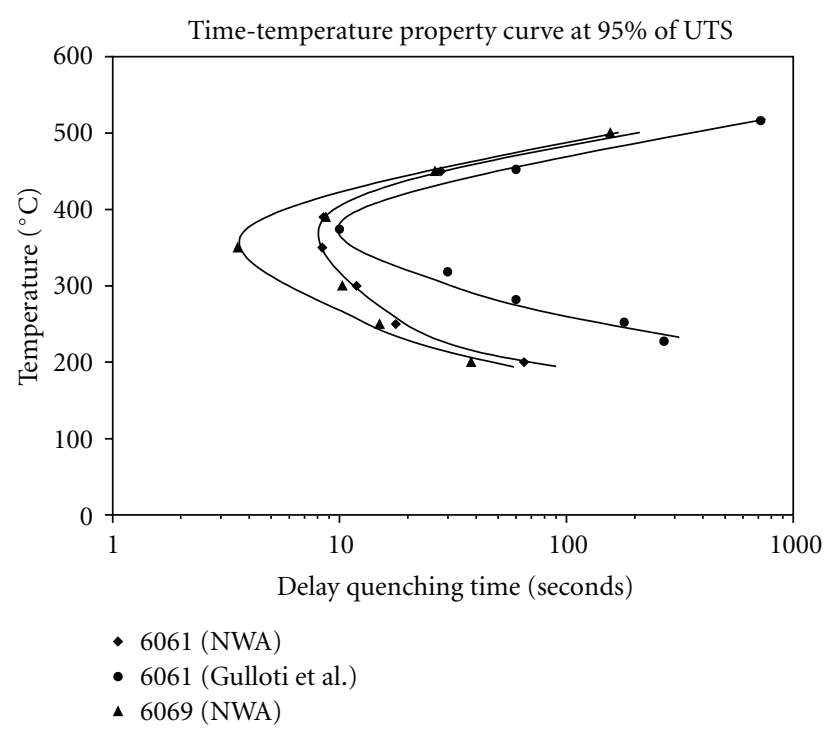

(b)

FIGURE 3: The time-temperature (a) yield, (b) UTS behavior of 6061-T6 and 6069-T6. Earlier work [4] on the 6061-T6 is also indicated.

indicates that mechanical properties of extruded 6069 are more sensitive to quench rate than those of extruded 6061 . This is consistent with the higher levels of $\mathrm{Mg}, \mathrm{Si}, \mathrm{Cu}$, and $\mathrm{Cr}$ reported in Table 1. The figure also reports other data for $6061[4,5]$. The increased amount of magnesium, silicon and chromium may increase $\mathrm{Mg}_{2} \mathrm{Si}$ concentration and nucleation rate, which is consistent with other studies [4]. The discrepancy between the 6061-T6 of this and the earlier study by Gullotti et al. [4], particularly at low temperatures, is not fully understood. It is curious that the 6061 of the present study shows more quench sensitivity, since the $\mathrm{Cr}$, $\mathrm{Mg}, \mathrm{Mn}, \mathrm{Si}$ are all (slightly) lower, than that of the Gullotti study. However, a study by Camero et al. [8] of alloy 6063 shows that vanadium accelerates the precipitation kinetics of the $\beta^{\prime}$ and $\beta^{\prime}$ phases. The absences of $\mathrm{V}$ in [4] may explain this discrepancy. Additionally, the ratio of $\mathrm{Mg}$ to $\mathrm{Si}$ was 1.34 in this study and 1.48 in [4], with the stoichiometric ratio being $\mathrm{Mg} / \mathrm{Si}=2$ as the $\beta$ precipitates are $\mathrm{Mg}_{2} \mathrm{Si}$. The resulting greater excess of $\mathrm{Si}$ in the current study may be favorable to the formation of $\beta^{\prime}$ phases due to the presence of heterogeneous nucleation sites $[9,10]$. Thus the increased quench sensitivity of this study, may be explained by the higher level of excess $\mathrm{Si}$ and the presence of vanadium. It should also be noted that the solution treatment temperature used in the present study for 6061 was $37^{\circ} \mathrm{C}$ higher than the standard suggested temperature, resulting in higher initial properties.

\section{Conclusions}

(1) 6061 and 6069 extruded aluminum alloys were solutiontreated and quenched to various temperatures in salt baths between 200 and $500^{\circ} \mathrm{C}$ for various times, followed by water quenching. The strength of extruded 6061-T6 and 6069-T6 alloys decreased as isothermal temperature decreased from $500-350^{\circ} \mathrm{C}$ and then increased again from $300-200^{\circ} \mathrm{C}$ for fixed times at temperature. The largest strength (yield and UTS) decreases occurred at isothermal temperature of $390^{\circ} \mathrm{C}$ and $350^{\circ} \mathrm{C}$ for extruded $6061-\mathrm{T} 6$ and $6069-\mathrm{T} 6$, respectively.

(2) Time-temperature curves at $95 \%$ of maximum yield stress and UTS for extruded 6061-T6 and 6069-T6 aluminum alloys indicate that mechanical properties of the new alloy 6069 are more sensitive to quench rate than those of the traditional alloy, 6061.

(3) The increased quenched sensitivity appears to be due to increased amount of magnesium, silicon, and chromium (and possibly $\mathrm{Cu}$ ), which may increase the $\mathrm{Mg}_{2} \mathrm{Si}$ concentration and nucleation rate.

\section{Acknowledgment}

This work was partially funded through the Northwest Aluminum Company, The Dalles, Ore, USA.

\section{References}

[1] S. C. Bergsma, M. E. Kassner, X. Li, and M. A. Wall, "Strengthening in the new aluminum alloy AA 6069," Materials Science and Engineering A, vol. 254, pp. 161-171, 1998.

[2] F. J. MacMaster, K. S. Chan, S. C. Bergsma, and M. E. Kassner, "Aluminum alloy 6069 part II: fracture toughness of 6061-T6 and 6069-T6," Materials Science and Engineering A, vol. 289, no. 1-2, pp. 54-59, 2000.

[3] X. Li, M. E. Kassner, and S. C. Bergsma, "Recrystallization behavior of rolled ingots of 6061 and 6069 aluminum alloys," Journal of Materials Engineering and Performance, vol. 9, pp. 416-423, 2000.

[4] D. V. Gullotti, J. Crane, and W. C. Setzer, "Isothermal transformation characteristics of several 6XXX series alloys," in Proceedings of 2nd International Aluminum Extrusion Technology Seminar, p. 249, Atlanta, Ga, USA, 1977. 
[5] H. Zoller and A. Ried, "Metallurgical aspects in development of AL MG SI alloys with a low sensitivity to quenching," $Z$ Metallkd, vol. 62, pp. 354-358, 1971.

[6] S. C. Bergsma, M. E. Kassner, X. Li, and R. S. Rosen, "The Quench Sensitivity of Hot Extruded 6061-T6 and 6069-T6 Aluminum Alloys," in Proceedings of THERMEC International Conference on Processing and Manufacturing of Advanced Materials, T. Chandra, K. Higashi, C. Suryanarayana, and C. Tome, Eds., CD Proceedings, Las Vegas, Nev, USA, December 2000, Session A4.

[7] L. F. Mondolfo, Aluminum Alloys: Structure and Properties, Butterworths, London, UK, 1976.

[8] S. Camero, E. S. Puchi, and G. Gonzalez, "Effect of $0.1 \%$ vanadium addition on precipitation behavior and mechanical properties of Al-6063 commercial alloy," Journal of Materials Science, vol. 41, no. 22, pp. 7361-7373, 2006.

[9] K. Matsuda, Y. Sakaguchi, Y. Miyata et al., "Precipitation sequence of various kinds of metastable phases in Al$1.0 \mathrm{mass} \% \mathrm{Mg} 2 \mathrm{Si}-0.4 \mathrm{mass} \% \mathrm{Si}$ alloy," Journal of Materials Science, vol. 35, no. 1, pp. 179-189, 2000.

[10] M. Muruyana and K. Hono, "Pre-precipitate clusters and precipitation processes in Al-Mg-Si alloys," Acta Materialia, vol. 47, pp. 1537-1548, 1999. 

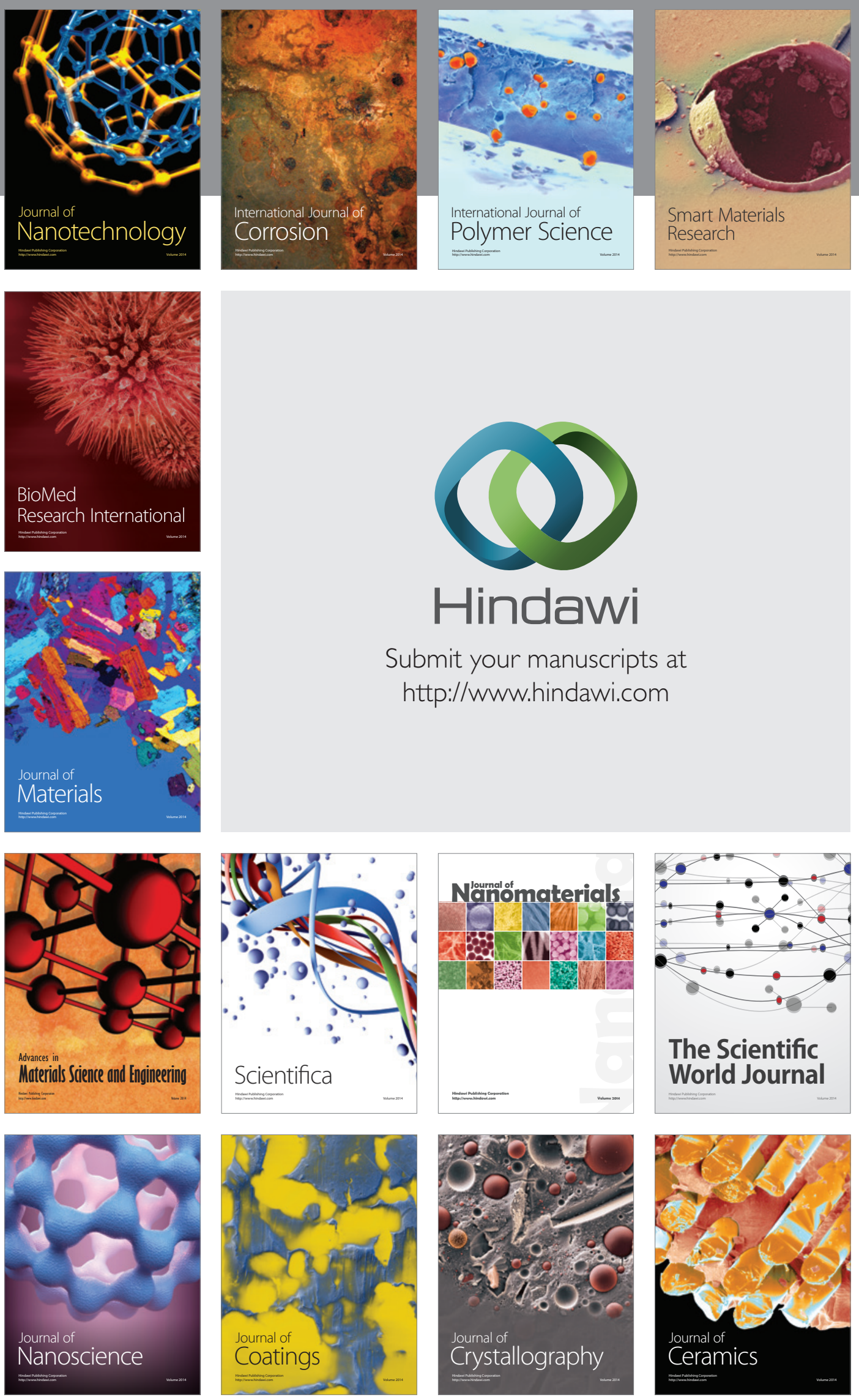

The Scientific World Journal

Submit your manuscripts at

http://www.hindawi.com

\section{World Journal}

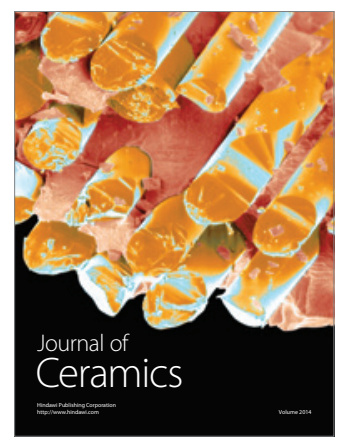

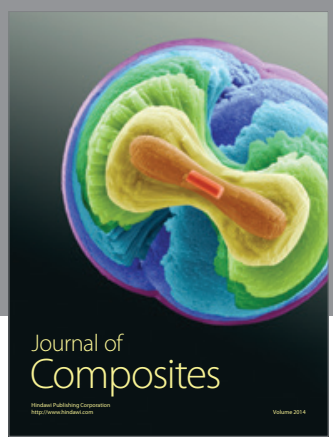
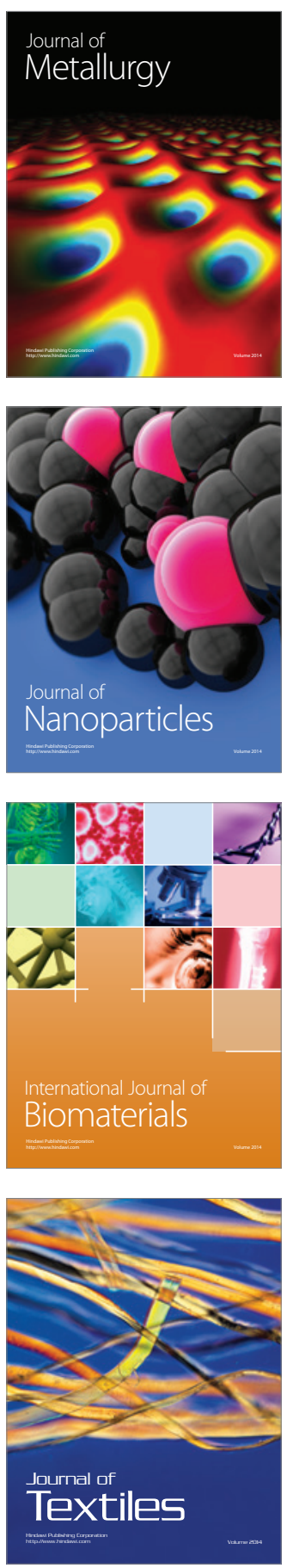